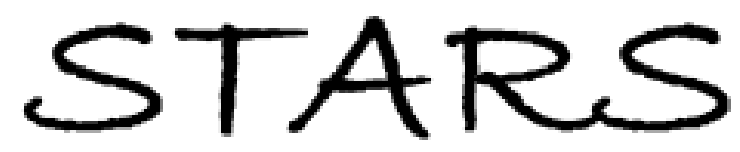

University of Central Florida

STARS

$1-1-2013$

\title{
Semiconductor laser monolithically pumped with a light emitting diode operating in the thermoelectrophotonic regime
}

\author{
X. Liu \\ University of Central Florida \\ G. Zhao \\ University of Central Florida \\ Y. Zhang \\ University of Central Florida \\ D. G. Deppe \\ University of Central Florida
}

Find similar works at: https://stars.library.ucf.edu/facultybib2010

University of Central Florida Libraries http://library.ucf.edu

This Article is brought to you for free and open access by the Faculty Bibliography at STARS. It has been accepted for inclusion in Faculty Bibliography 2010 s by an authorized administrator of STARS. For more information, please contactSTARS@ucf.edu.

\section{Recommended Citation}

Liu, X.; Zhao, G.; Zhang, Y.; and Deppe, D. G., "Semiconductor laser monolithically pumped with a light emitting diode operating in the thermoelectrophotonic regime" (2013). Faculty Bibliography 2010s. 4324. https://stars.library.ucf.edu/facultybib2010/4324

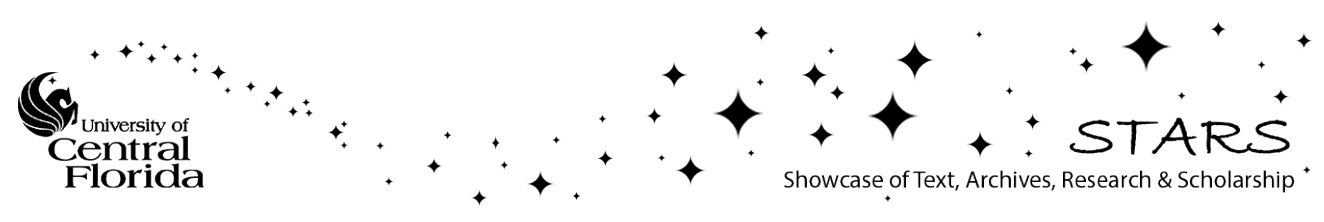




\section{Semiconductor laser monolithically pumped with a light emitting diode operating in the thermoelectrophotonic regime}

Cite as: Appl. Phys. Lett. 102, 081116 (2013); https://doi.org/10.1063/1.4793656

Submitted: 19 November 2012 . Accepted: 14 February 2013 . Published Online: 28 February 2013

X. Liu, G. Zhao, Y. Zhang, and D. G. Deppe
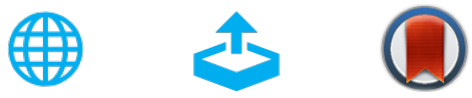

\section{ARTICLES YOU MAY BE INTERESTED IN}

Thermally enhanced blue light-emitting diode

Applied Physics Letters 107, 121109 (2015); https://doi.org/10.1063/1.4931365

Room temperature thermo-electric pumping in mid-infrared light-emitting diodes

Applied Physics Letters 103, 183513 (2013); https://doi.org/10.1063/1.4828566

Photon recycling effect on electroluminescent refrigeration

Journal of Applied Physics 111, 014511 (2012); https://doi.org/10.1063/1.3676249

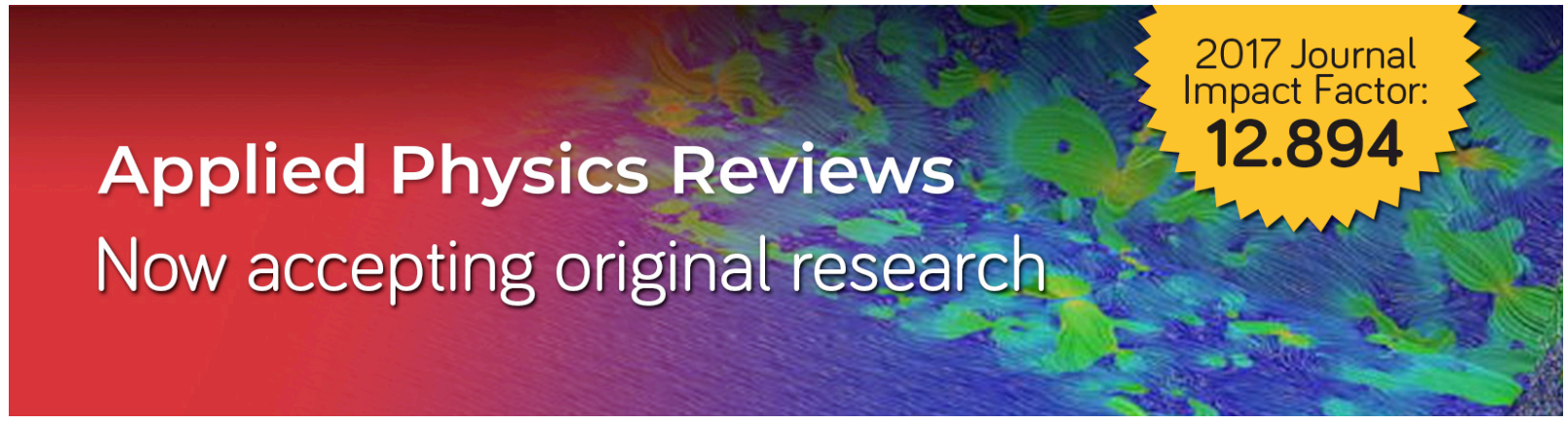




\title{
Semiconductor laser monolithically pumped with a light emitting diode operating in the thermoelectrophotonic regime
}

\author{
X. Liu, G. Zhao, Y. Zhang, and D. G. Deppe \\ College of Optics and Photonics, CREOL, College of Optics and Photonics, University of Central Florida, \\ Orlando, Florida 32816, USA
}

(Received 19 November 2012; accepted 14 February 2013; published online 28 February 2013)

\begin{abstract}
Data are presented on a monolithic chip that integrates a quantum well semiconductor laser with a high efficiency light emitting diode (LED), with the LED used to optically pump the laser. The LED operates in the thermoelectrophotonic regime that can produce heat absorption, offering the possibility of heat pump action. The internal optical pumping also offers the possibility of very low internal loss in the laser and the prospect of reaching greater than unity power conversion efficiency in the laser chip. The integrated laser chip is operated and tested under continuous-wave room temperature operation. (C) 2013 American Institute of Physics. [http://dx.doi.org/10.1063/1.4793656]
\end{abstract}

Semiconductor light emitting diodes (LEDs) can operate in a thermoelectrophotonic (TEP) regime for which their power conversion efficiency may exceed unity. In such operation the LED radiates more optical power than the power it draws from an external electrical power source. While the TEP regime physics that can produce greater than unity power conversion efficiency has been understood for some time, ${ }^{1-5}$ only recently has it been demonstrated in an LED. ${ }^{6}$

The experimental demonstration of the greater than unity efficiency so far suffers major drawbacks for applications mainly because the LED scheme that has been demonstrated requires extracting the spontaneous emission from the semiconductor chip. ${ }^{6}$ This light extraction suffers from Snell's law and a small escape cone from the LED chip. On the other hand, a laser that operates with greater than unity efficiency would be much more useful and quite likely a technological revolution because of its directional emission and high extraction efficiency. Such a device could therefore produce usable power levels while operating in the selfcooling regime. However, as opposed to an LED, a diode laser requires a voltage drive that exceeds the laser photon energy, while the TEP regime needed for greater than unity efficiency in an LED requires a voltage drive that is less than the photon energy. Therefore it does not appear possible that a diode laser operating alone can break the unity efficiency barrier.

Modern semiconductor technology, however, enables the monolithic integration of an LED that can operate in the TEP regime with greater than unity efficiency with a semiconductor laser, for which the LED acts as an optical pump as well as a TEP heat pump to the laser. In fact, as we show below, this type of integration eliminates the need to extract the LED emission from the chip and instead benefits from Snell's law. Our calculations based on material parameters indicate that the combination could result in an integrated laser chip for which the laser output power exceeds unity efficiency with respect to the chip's electrical input power.

In this letter we present the demonstration of the monolithic integration of such an LED pumped laser chip and present data on its operation. We describe advantages of using the TEP effect that comes from absorbing the LED light internal to the chip, mainly avoiding the usual low extraction efficiency caused by Snell's law of the LED light. We also describe further advantages of the integrated chip for producing very low internal optical loss in the semiconductor laser waveguide, due to integration of the monolithic LED optical pump.

Figure 1 shows a schematic of the integrated laser chip. The LED is either bulk GaAs or AlGaAs, and semiconductor laser uses a single InGaAs quantum well. Both the LED and laser are clad between two mirrors. The p-type mirror is comprised of two p-type pairs of quarter-wave layers of $\mathrm{Al}_{0.1} \mathrm{Ga}_{0.9} \mathrm{As} / \mathrm{Al}_{0.67} \mathrm{Ga}_{0.33} \mathrm{As}$, followed by phase matching $\mathrm{p}$ type $\mathrm{Al}_{0.1} \mathrm{Ga}_{0.9} \mathrm{As}$ and $\mathrm{p}^{+} \mathrm{GaAs}$ contact layers and a postgrowth deposited Ag mirror. The Ag mirror also serves as an electrical p-contact to the LED. The n-type mirror is based on 16 quarter wave pairs of $\mathrm{Al}_{0.1} \mathrm{Ga}_{0.9} \mathrm{As} / \mathrm{AlAs}$. The semiconductor laser uses $\mathrm{Al}_{0.3} \mathrm{Ga}_{0.7} \mathrm{As}$ cladding layers, a $0.5 \mu \mathrm{m}$ thick GaAs waveguide layer, and a $60 \AA \operatorname{In}_{0.2} \mathrm{Ga}_{0.8}$ As quantum well active region. All layers of the laser except the quantum well active layer are doped n-type at $\sim 10^{17} \mathrm{~cm}^{-3}$. Above the laser is grown a p-n bulk LED with an undoped active thickness of $1.5 \mu \mathrm{m}$ and cladding $\mathrm{p}-\mathrm{n} \mathrm{Al}_{0.1} \mathrm{Ga}_{0.9} \mathrm{As}$ electrical injection layers. The two mirror stacks trap the spontaneous emission of the LED, which undergoes photon recycling and ultimately absorption in the laser waveguide.

Figure 2 shows $300 \mathrm{~K}$ and $77 \mathrm{~K}$ photoluminescence from the as-grown structure. The epitaxial structure is excited using a $15 \mathrm{~mW}$ HeNe laser operated at $0.632 \mu \mathrm{m}$ with a $1 \mathrm{~mm}$ diameter excitation spot. The HeNe pump is mainly absorbed in the LED layers. The GaAs LED active region then also pumps the laser waveguide and quantum well in photoluminescence. The comparison is made between the $300 \mathrm{~K}$ and $77 \mathrm{~K}$ photoluminescence to estimate the GaAs emission efficiency. The emission spectra, taken from the epitaxial surface, show the GaAs LED emission peak at $0.87 \mu \mathrm{m}$ at $300 \mathrm{~K}$ and $0.83 \mu \mathrm{m}$ at $77 \mathrm{~K}$, and the $\operatorname{In}_{0.2} \mathrm{Ga}_{0.8} \mathrm{As}$ quantum well emission of the laser at $0.98 \mu \mathrm{m}$ at $300 \mathrm{~K}$ and $0.93 \mu \mathrm{m}$ at $77 \mathrm{~K}$. This emission is spectrally modified by the vertical cavity structure of the upper and lower mirrors but clearly shows both the GaAs LED emission and the $\mathrm{In}_{0.2} \mathrm{Ga}_{0.8} \mathrm{As}$ quantum well emission. Because of the thicknesses of the LED layers including the $\mathrm{p}$ and $\mathrm{n} \mathrm{Al}_{0.1} \mathrm{Ga}_{0.9} \mathrm{As}$ injection layers, the $\mathrm{In}_{0.2} \mathrm{Ga}_{0.8}$ As quantum well emission can 


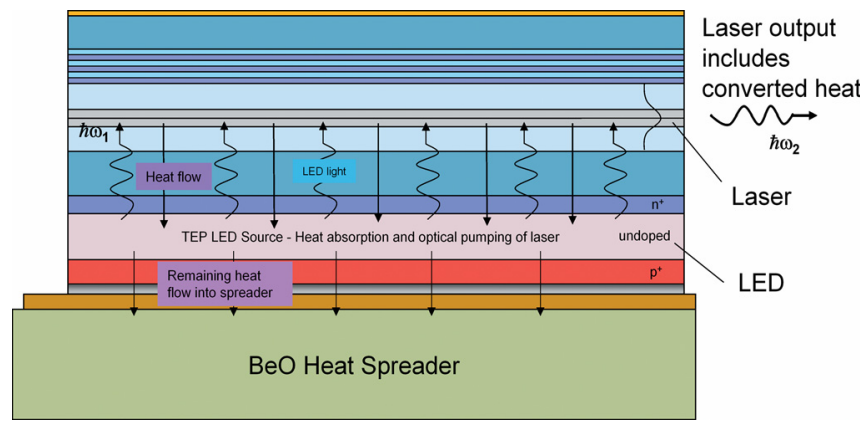

FIG. 1. Schematic illustration of the GaAs LED integrated with the semiconductor laser. The LED is electrically biased and optically pumps the laser waveguide and quantum well. The LED is designed to operate in the regime of thermoelectrophotonic heat pump, absorbing heat as it optically pumps the laser.

be assumed to result from optical pumping by the GaAs LED emission towards the substrate. Electrical contacting to the GaAs LED is through the Ag mirror/contact placed on the upper p-side of the integrated chip and through a GeAu alloyed contact formed on the GaAs $\mathrm{n}^{+}$substrate. The electron current of the n-side is therefore passed through the laser waveguide and quantum well.

The laser and LED spectral emission are measured driving the chip quasi-continuous-wave without heat sinking, simply probing the chip placed on a metal contact. No soldering or other heat sinking is used so that the $40 \mathrm{~ms}$ electrical pulses of the quasi-continuous-wave operation cause some heating of the chip. Figure 3 shows the electroluminescence spectra measured from one facet of the chip both below and above threshold. While GaAs LED emission can be measured below threshold, only $\mathrm{In}_{0.2} \mathrm{Ga}_{0.8} \mathrm{As}$ quantum well lasing is measured above threshold. In fact the GaAs LED injection current density at threshold of $333 \mathrm{~A} / \mathrm{cm}^{2}$ is far below the estimated value of $9000 \mathrm{~A} / \mathrm{cm}^{2}$ needed to invert the electron-hole population of the GaAs LED. If the GaAs LED region did become inverted, its thickness would easily support lasing end-to-end in the GaAs LED.

Numerous laser and LED designs have been investigated so far, with most showing room temperature laser

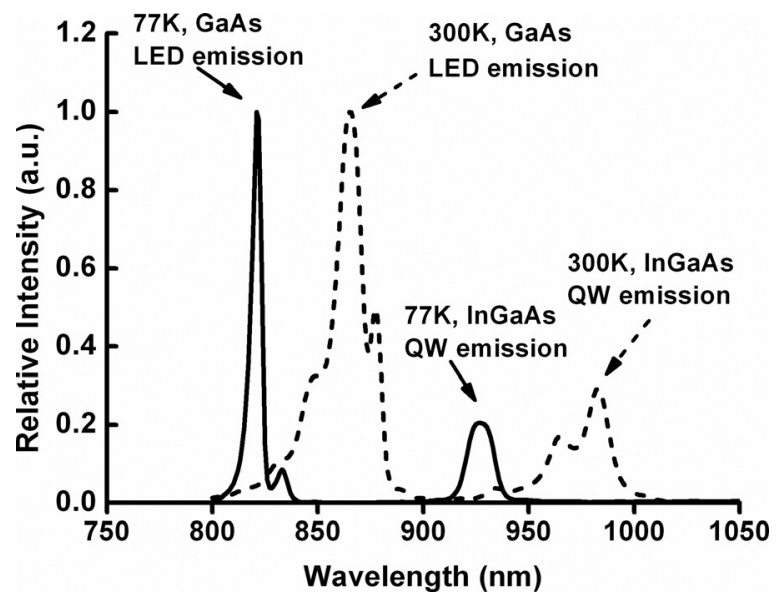

FIG. 2. Photolumenescence measured at $300 \mathrm{~K}$ and $77 \mathrm{~K}$ from the as-grown epitaxial sample. The HeNe pump light is absorbed in the GaAs LED region, which is shown at $870 \mathrm{~nm}$ at $300 \mathrm{~K}$ (dashed curve) and $830 \mathrm{~nm}$ at $77 \mathrm{~K}$ (solid curve). The GaAs spontaneous emission pumps the quantum well at $980 \mathrm{~nm}$ at $300 \mathrm{~K}$ (dashed curve) and at $930 \mathrm{~nm}$ at $77 \mathrm{~K}$ (solid curve).

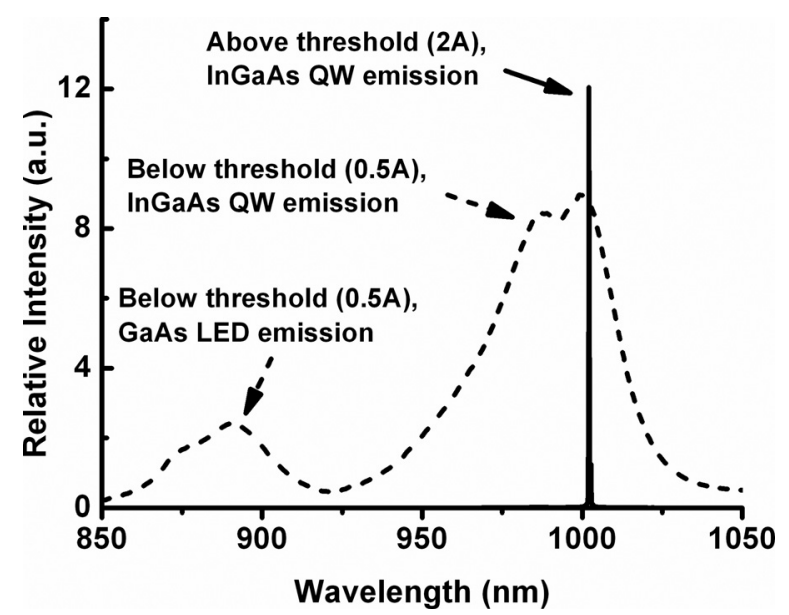

FIG. 3. Electroluminescence measured from the chip at two different bias levels. The below threshold level at $0.5 \mathrm{~A}$ shows both the GaAs emission and the quantum well emission. At $2 \mathrm{~A}$ only laser emission from the quantum well occurs.

operation. The light vs. current curve of one of the higher power integrated chips is shown in Figure 4. This sample has $\mathrm{Al}_{0.02} \mathrm{Ga}_{0.98}$ in LED active region, three quantum wells in laser structure, and 10 pairs of $\mathrm{p}$ mirror layers. The laser emission is measured driving the chip continuous-wave with $\mathrm{BeO}$ heat sink, and the chip is p-side down mounted on the $\mathrm{BeO}$ heat sink with AuSn solder. The lasing threshold of the $\mathrm{In}_{0.2} \mathrm{Ga}_{0.8} \mathrm{As}$ quantum well for a $120 \mu \mathrm{m}$ wide electrical contact on the LED and $0.5 \mathrm{~cm}$ long cavity is measured to be $2 \mathrm{~A}$ under room temperature operation. The $2 \mathrm{~A}$ lasing threshold corresponds to a current density of $333 \mathrm{~A} / \mathrm{cm}^{2}$, which is only a factor of two higher than for an electrically injected p-n diode laser of similar waveguide and quantum well design and contacting area. The slope efficiency of this device is $12 \%$.

Finally we note that optical absorption of the LED light by the laser waveguide is largely due to off-normal radiation modes due to their much larger solid angle of emission. These off-normal radiation modes are more readily trapped between the LED and laser waveguide to increase absorption. We have estimated this absorption in the current

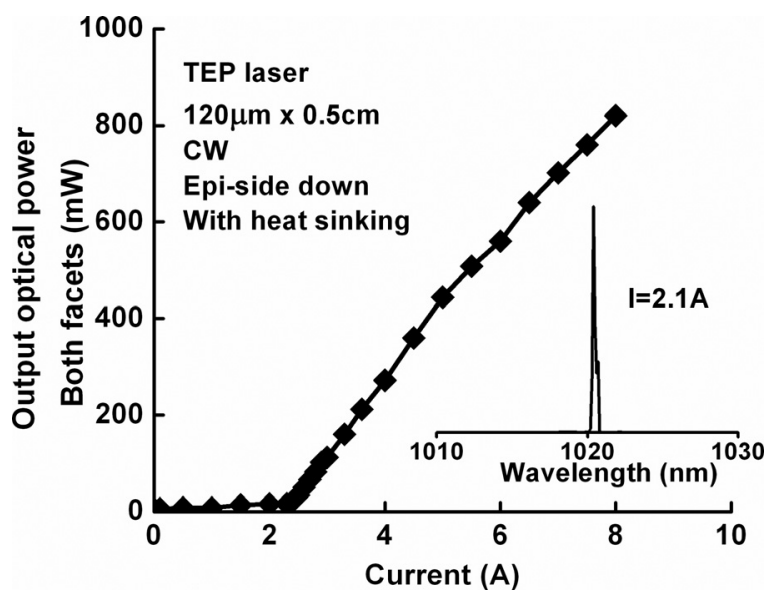

FIG. 4. Light vs. current curve from the chip measured CW from both facets. Driving the LED electrically optically pumps the quantum well laser, which produces the laser emission shown in the inset. The stripe dimensions are $120 \mu \mathrm{m} \times 0.5 \mathrm{~cm}$. 
structures to be greater than $90 \%$. Further optimization and simulation indicate that the absorption between the LED and laser quantum well active region could be increased potentially to as high as $>98 \%$.

In summary, we have shown that an internal LED optical pump can be monolithically integrated with a semiconductor laser and operated in a regime for which the LED can be optically absorbing while pumping the laser into continuous wave operation at room temperature. Heat absorption is expected to result for sufficiently high internal quantum efficiency in the bulk LED, and this is currently being explored. Simulations also show that with sufficiently low threshold in the laser and sufficiently small quantum defect between the LED pump and quantum well lasing transition, it may be possible for the integrated laser chip to enter the self-cooling regime with greater than unity power conversion efficiency. When optimized, low internal optical loss is expected for the semiconductor laser due to elimination of p-doping from the cladding layers and removal of the need for hole injection, giving the prospect for increased brightness from the semiconductor laser.

Parts of this research have been supported by DARPA through the Army Research Laboratory under Grant No. W31P4Q1110013 and by the National Science Foundation through Award No. 1034187.

${ }^{1}$ R. J. Keyes and T. M. Quist, Proc. IRE 50, 1822 (1962).

${ }^{2}$ G. C. Dousmanis, C. W. Mueller, H. Nelson, and K. G. Petzinger, Phys. Rev. 133, A316 (1964).

${ }^{3}$ P. Berdahl, J. Appl. Phys. 58, 1369 (1985).

${ }^{4}$ K. C. Lee and S. T. Yen, J. Appl. Phys. 111, 014511 (2012).

${ }^{5}$ H. Oskari, J. Oksanen, and J. Tulkki, J. Appl. Phys. 107, 033105 (2010).

${ }^{6}$ P. Santhanam, D. J. Gray, and R. J. Ram, Phys. Rev. Lett. 108, 097403 (2012). 